\title{
The Psychological Impact of the COVID-19 Pandemic on Jordanian Healthcare Workers
}

\author{
Fadi Fawaris, King Hussein Cancer Center, Jordan \\ (iD) https://orcid.org/0000-0001-8461-3733 \\ Elham H. Othman, The University of Jordan, Jordan \\ Mohammed AlBashtawy, Al Al-Bayt University, Jordan \\ Ahmad Abu Alfwares, King Abdullah University Hospital, Jordan
}

\begin{abstract}
Healthcare workers face incomparable work and psychological demands that are amplified throughout the COVID-19 pandemic. This study aimed to investigate the psychological impact of the COVID-19 pandemic on healthcare workers in Jordan. A cross-sectional design was used. Data was collected using an online survey during the outbreak of COVID-19. Overall, of the 312 healthcare workers, almost $38 \%$ and $36 \%$ presented with moderate to severe anxiety and depression, respectively. Nurses reported more severe symptoms than other healthcare workers, and both anxiety and depression were negatively correlated with well-being. Getting infected was not an immediate worry among healthcare workers; however, they were worried about carrying the virus to their families. Stakeholders must understand the impact of COVID-19 on healthcare workers and plan to provide them with the required psychological support and interventions at an early stage.
\end{abstract}

\section{KEYWORDS}

Anxiety, COVID-19, Depression, Healthcare Workers, Jordan, Psychological Impact

\section{INTRODUCTION}

The emerging Coronavirus disease-19 (COVID-19) is caused by the novel coronavirus (SARS-CoV-2), which was reported first in December 2019. Due to the rapid worldwide spread, the World Health Organization (WHO) declared the COVID-19 as a public health emergency in January 2020 (WHO, 2021a). By the end of January 2021, over 102 million COVID-19 cases and 2,209,195 deaths have been reported to WHO (WHO, 2021b).

In Jordan, the infected individuals with COVID-19 were isolated and treated in specialized units. By the end of January 2021, the Jordanian Ministry of Health announced 326,855 confirmed cases; and 4,316 deaths (Ministry of Health, 2021). The Jordanian government-imposed home confinement instructions, lockdown, and movement restrictions followed by a partial lockdown until further notice. These confinement measures and the fear of the infection itself may negatively impact the psychological and spiritual status of the frontline healthcare workers (Fawares et al.,2020).

Healthcare workers in different disciplines face incomparable work and psychological demands. Moreover, this emergent situation sets out an extreme encumbrance on health services, as many healthcare workers work in highly demanding environments with limited resources (Hu \& Huang, 2020). Experiencing more significant physical and psychological stress symptoms can adversely

\section{DOI: 10.4018/IJRQEH.289635}

This article published as an Open Access article distributed under the terms of the Creative Commons Attribution License (http://creativecommons.org/licenses/by/4.0/) which permits unrestricted use, distribution, and production in any medium, provided the author of the original work and original publication source are properly credited. 
affect health well-being. The after-effect stress, which does not reflect the real stress that participants experienced during the event itself, was examined and documented by several studies (Jackson \& Maslach, 1982; Klein et al., 2004; Möschl et al., 2017)(Möschl et al., 2017). Thus, an urgent need to identify the possible psychological impacts of the pandemic on healthcare workers.

\section{METHODOLOGY}

The current study aimed to explore the psychological impact that is imposed by the COVID-19 pandemic on healthcare workers in Jordan.

A cross-sectional descriptive design was used to collect data from healthcare workers in Jordan using a self-reported questionnaire. The target population consisted of nurses, physicians, pharmacists, and other hospital staff who work in private and government hospitals. The data was collected over eight weeks and was conducted while the confirmed and suspect COVID-19 cases in Jordan expanded quickly. Along with the increased curve and the recommendations of the WHO to maintain social distance and avoid interpersonal contact, an online survey was used for the data collection.

The questionnaire consisted of four sections: Demographic data, Self-Rating Anxiety Scale, SelfRating Depression Scale, and the WHO (Five) Well-Being Index. The participants were given a brief overview of the study's purpose and process. Besides, their right to participate freely was assured by clicking a "continue to survey" link. All responses were handled confidentially and anonymously, and all data were stored securely in the primary investigator's personal computer. No one had access to the data except for the research team.

\section{- Instruments}

General demographic information was obtained, including age, gender, Marital status, educational level, specialty (clinical work area), length of employment (experience), and scheduled work pattern. The Participants were asked about their worries and coping strategies, history of anxiety or depression, family history of anxiety or depression, personal protective equipment (PPE) availability, and receiving any educational sessions about new COVID-19 precaution measures in their hospitals.

\section{- The Self-Rating Anxiety Scale (SAS)}

The self-rated anxiety scale (SAS) is a self-administered Likert questionnaire ranging from 1 (none of the time) to 4 (most of the time). The SAS consists of 20-items, 15 of them about increased anxiety level, and five items about decreased anxiety level. Overall the minimum score is 20 and the highest is 80 , higher scores suggesting higher anxiety levels. The index anxiety score ranges from 25 to 100 , with an acceptable cutoff point of ${ }^{3} 50$.

\section{- The Self-Rating Depression Scale (SDS)}

The self-rated scale of depression (SDS) is a self-administered Likert questionnaire ranging from 1 (none of the time) to 4 (most of the time). The SDS consists of 20-items, and the raw scores are converted to the depression severity index with four groups of severity; normal (below 50), mild depression (50-59), moderate depression (60-69), and severe depression (above 70).

- WHO (Five) Well-Being Index scale 
The Five Well-Being Index (WHO-5) of the WHO is a brief, self-reported index of current mental well-being. The (WHO-5) index consists of five statements with responses ranging from 0 (At no time) and 5 (All of the time), with 0 representing the worst possible well-being and 100 representing the best well-being.

\section{Statistical Analysis}

Statistical data analysis was conducted using SPSS version 21.0. At first, descriptive statistics were used to analyze the demographics data and the incidence of anxiety and depression. Then, Pearson $r$ correlation test was used to measure the relationship between the continuous variables, while the point biserial correlation test measured the relationship between dichotomous and continuous variables. Predictors of anxiety and depression were found by regression analysis.

\section{FINDINGS}

- Characteristics of the study participants

A total of 312 healthcare workers participated in this study. The majority of participants were men $(n=174,55.8 \%)$, nurses $(n=182,58.3 \%)$, aged from 22 to $67(M=34.16, S D=8.06)$. There was a variation in the educational level and experiences; however, the majority held bachelor's degree ( $\mathrm{n}=$ $178,56.9 \%)$ and were from governmental hospitals $(n=165,52.7 \%)$, working in general units $(n=126$, 40.3\%). Moreover, respondents' experience ranged from 6 months to 15 years; the majority worked rotating shifts $(n=200,63.9 \%)$. Detailed demographics are presented in Table (1).

-The availability of PPE

In general, Most respondents $(n=188,60.1 \%)$ confirmed that sufficient PPEs were available in their hospitals during the COVID-19 pandemic, while the remaining respondents $(n=124,39.6 \%)$ mentioned that it was not available in the units.

- Training about COVID-19

In response to the question, "Have you been trained by your institute about new precautionary measures of COVID-19?", The majority of the respondents $(n=178,56.9 \%)$ denied receiving any kind of training.

\section{- Levels of depression and anxiety}

The majority of participants denied a previous history of anxiety or depression disorders $(\mathrm{n}=258,82.4 \%)$ or family history $(\mathrm{n}=268,85.6 \%)$. Table (2) shows the psychological health of the participants throughout the outbreak. Of the 312 participants, near $39.4 \%$ had no anxiety symptoms, while $38 \%$ expressed moderate to severe anxiety. Regarding the depressive symptoms, almost $39.4 \%$ of respondents showed no sign of depression, while $36 \%$ presented with moderate to severe depression. In general, nurses experience more severe anxiety and depression than other healthcare workers. Furthermore, more women $(n=23,7.3 \%)$ reported severe anxiety and depression results than men $(n=15,4.8 \%)$. 
Table 1. Demographic charachterestics of the participants $(N=312)$

\begin{tabular}{|c|c|c|c|}
\hline $\mathbf{n} \%$ & Mean (SD) & Range & Item \\
\hline & & & Gender \\
\hline $174(55.8 \%)$ & & & Male \\
\hline \multirow[t]{4}{*}{$138(44.2 \%)$} & & & Female \\
\hline & $34.16(8.06)$ & $22-56$ & Age (Years) \\
\hline & $20(6.5)$ & $1-33$ & Experience (Years) \\
\hline & & & Occupation \\
\hline $182(58.3 \%)$ & & & Nurses \\
\hline $104(33.3 \%)$ & & & Physicians \\
\hline $10(3.2 \%)$ & & & Pharmacists \\
\hline $6(1.9 \%)$ & & & Administratives \\
\hline $6(1.9 \%)$ & & & Technicians \\
\hline \multirow[t]{2}{*}{$4(1.2 \%)$} & & & Social workers \\
\hline & & & Education \\
\hline $30(9.6 \%)$ & & & College degree \\
\hline $178(56.9 \%)$ & & & Bachelor degree \\
\hline $86(27.5 \%)$ & & & Master degree \\
\hline \multirow[t]{2}{*}{$18(5.8 \%)$} & & & Doctorate or above degree \\
\hline & & & Practice setting \\
\hline $165(53.7 \%)$ & & & Governmental \\
\hline $124(39.6 \%)$ & & & Private Sector \\
\hline \multirow[t]{2}{*}{$23(7.4 \%)$} & & & University or military hospital \\
\hline & & & Clinical working area \\
\hline $126(40.3 \%)$ & & & General units \\
\hline $64(20.4 \%)$ & & & A quarantine unit \\
\hline $46(14.7 \%)$ & & & Intensive care unit \\
\hline $20(6.4 \%)$ & & & Department of respiration \\
\hline $17(5.4 \%)$ & & & Emergency unit \\
\hline $16(5.1 \%)$ & & & Department of Infectious disease \\
\hline \multirow[t]{2}{*}{$14(4.5 \%)$} & & & Administration \\
\hline & & & Schedule work pattern \\
\hline $200(64.1 \%)$ & & & Rotating \\
\hline \multirow[t]{2}{*}{$112(35.9 \%)$} & & & Straight \\
\hline & & & The Availability of PPE \\
\hline $118(60.1 \%)$ & & & Yes \\
\hline \multirow[t]{2}{*}{$124(39.6 \%)$} & & & No \\
\hline & & & COVID-19 training \\
\hline $134(42.8 \%)$ & & & Yes \\
\hline $178(56.9 \%)$ & & & No \\
\hline
\end{tabular}


Table 2. Number of healthcare workers depression and anxiety level $(\mathrm{N}=312)$

\begin{tabular}{|l|l|l|l|l|}
\hline $\begin{array}{l}\text { Item } \\
\text { severity }\end{array}$ & Normal & Mild & Moderate & Severe \\
\hline Anxiety & $123(39.4 \%)$ & $70(22.4 \%)$ & $52(16.6 \%)$ & $67(21.4)$ \\
\hline Depression & $138(44 \%)$ & $62(20 \%)$ & $28(9 \%)$ & $84(27 \%)$ \\
\hline
\end{tabular}

\section{RELATIONSHIP BETWEEN SAS, SDS, AND WELL-BEING}

The results revealed a significant positive strong relationship between SAS and SDS $(\mathrm{r}=.793, \mathrm{P}<$ $.001)$. On the other hand, there were significant weak negative relationships between well-being and SAS $(r=-.212, \mathrm{P}<.001)$ and SDS $(\mathrm{r}=-.274, \mathrm{P}<.001)$. Participants who had received training about COVID-19 had lower levels of anxiety $(\mathrm{rpb}=-0.231, \mathrm{P}<.001)$ and depression $(\mathrm{rpb}=-0.241, \mathrm{P}<.001)$.

Table 3. Relationship between SAS, SDS, and well-being ( $N=312)$

\begin{tabular}{|l|l|l|l|l|}
\hline$\bullet$ & SAS & SDS & Well-being & COVID-19 Training \\
\hline SAS & 1 & & & \\
\hline SDS & $.793^{*}$ & 1 & & \\
\hline Wellbeing & $-.212^{*}$ & $-.274^{*}$ & 1 & \\
\hline COVID 19 Training & $-.231 *$ & $-.241^{*}$ & - & 1 \\
\hline *Correlation is significant at the 0.01 level (2-tailed). \\
\hline
\end{tabular}

- Concerns and coping strategies

The respondents were queried about their worries while working with patients diagnosed with COVID-19; the majority reported that becoming infected was not an instant concern to them $(n=152$, $48.6 \%$ ). The second reason for worrying among participants was that they did not wish to cause panic to their own families and were worried about carrying the virus to their homes $(n=88,28.1 \%)$. Furthermore, about $17 \%$ of the participants $(n=52)$ did not know how to convince patients who refuse the hospital quarantine measures or did not collaborate with them because of anxiety. Lastly, about few participants $(n=20,6.4 \%)$ were worried about the lack of PPEs and reported feelings of incompetence when confronted with critical situations.

The respondents reported using several coping strategies during the pandemic to alleviate their worries and stress. The most-reported strategies were praying; followed by reading, socialization with family and friends, and listening to music; engaging in physical activity; and staying at home $(34.9 \%, 31.1 \%, 23.7 \%$, and $10.2 \%$, consecutively).

- Contributing factors of anxiety and depression

Analysis of Anxiety and depression risks showed a significantly higher prevalence of anxiety and depression among the participants who have previous anxiety or depression history $(\mathrm{OR}=2.52$, 95\% CI 1.52-3.43), previous family history of anxiety or depression ( $\mathrm{OR}=1.52,95 \% \mathrm{CI} 1.05-1.91)$, lack of PPE $(\mathrm{OR}=2.32,95 \% \mathrm{CI} 1.29-3.51)$, less years of experience $(\mathrm{OR}=1.92,95 \% \mathrm{CI} 1.14-1.97)$, working in quarantine unit $(\mathrm{OR}=3.23,95 \% \mathrm{CI} 1.78-4.57)$, living with old age parents $(\mathrm{OR}=2.13$, 
95\% CI 1.02-2.07) and the did not have COVID-19 training (OR=2.27, 95\% CI 1.15-3.38). While praying and reading $(\mathrm{OR}=0.77,95 \% \mathrm{CI} 0.57-0.87)$, engaging in physical activities $(\mathrm{OR}=0.54,95 \%$ CI 0.42-0.63), and contacting with family and friends ( $\mathrm{OR}=0.86,95 \% \mathrm{CI} 0.39-0.91)$ were associated with a lower risk of psychological problems.

\section{DISCUSSION}

The aim of the current study was to explore the psychological impact of the COVID-19 pandemic on healthcare workers in Jordan. A significant number of healthcare workers showed moderate to severe symptoms of psychological problems (depression and anxiety), which corresponds with a recent study that surveyed 1,257 healthcare workers at 34 hospitals (Lai et al., 2020). The latter study reported that healthcare providers who care for COVID-19 patients experience significantly higher depression and anxiety levels. These results imply that appropriate screening and support for the psychological status must maintain the workers' well-being.

The negative correlation between receiving COVID-19 training and the level of depression and anxiety that we revealed is congruent with Chen et al. (2020), who reported that healthcare workers who received special training had lower depression and anxiety levels. This finding suggests that hospitals can alleviate the stress and increase the frontline workers' reassurance with simple measures such as conducting appropriate training about COVID-19 prevention.

In terms of healthcare workers' concerns, we found that they worry the most about carrying the virus to their families, working with limited protective supplies, and dealing with patients' anxiety. Previous studies reported similar concerns (Hu \& Huang, 2020; Sahashi et al., 2020; Wu et al., 2020), indicating that similar pandemic impacts might occur globally across different cultures. Hospitals have to provide a place where healthcare workers could isolate themselves from their families. Moreover, healthcare workers need to be trained on proper psychological distress management to deal with distressed patients in such pandemic situations.

In this study, we identified several factors that contribute to anxiety and depression among healthcare workers. Similar factors were reported previously, including direct contact with COVID-19 patients, such as working in a quarantine unit (Liu et al., 2020); worry about infecting others, such as family members (Wu et al., 2020); and previous anxiety or depression history (Zhu et al., 2020). During times of pandemics, hospitals are required to identify these factors and provide adequate support to the healthcare workers. Facilitating activities that help frontline workers cope with different stressors will improve their well-being and minimize pandemics' impact on their psychological health (Cai et al., 2020; Heath et al., 2020). According to our participants, these activities include religious practices, reading, physical activities, and socialization with family and friends. Similar and other strategies were reported in the literature, including distraction, social support, problem-solving, and keeping a positive attitude (Chew et al., 2020, Fawaris, 2021).

\section{CONCLUSION AND FUTURE RESEARCH AVENUES}

Protecting healthcare workers' psychological health is necessary to enhance their well-being; nevertheless, the best method to do this during the pandemic stills hazy. This study exposed the psychological symptoms burden among Jordanian healthcare workers through the pandemic of COVID-19. These findings will help stakeholders to understand the impact of COVID-19 on healthcare workers and plan to provide them with psychological screening, support, and interventions at an early phase. Further studies to explore the long-term effects of the COVID-19 pandemic and the possible interventions to alleviate these effects are recommended. 


\section{CONFLICTS OF INTEREST}

The authors declare no conflict of interest. 


\section{REFERENCES}

Cai, H., Tu, B., Ma, J., Chen, L., Fu, L., Jiang, Y., \& Zhuang, Q. (2020). Psychological impact and coping strategies of frontline medical staff in Hunan between January and March 2020 during the outbreak of coronavirus disease 2019 (COVID) in Hubei, China. Medical Science Monitor, 26, 1-16. doi:10.12659/MSM.924171 PMID:32291383

Chen, Q., Liang, M., Li, Y., Guo, J., Fei, D., Wang, L., \& Wang, J. (2020). Mental health care for medical staff in China during the COVID-19 outbreak. The Lancet. Psychiatry, 7(5), e27. doi:10.1016/S2215-0366(20)30078-X PMID:32085839

Chew, Q. H., Wei, K. C., Vasoo, S., Chua, H. C., \& Sim, K. (2020). Narrative synthesis of psychological and coping responses towards emerging infectious disease outbreaks in the general population: Practical considerations for the COVID-19 pandemic. Singapore Medical Journal, 61(7), 350-356. doi:10.11622/smedj.2020046 PMID:32241071

Fawares, F., Ibdah, R., Ammar, K., Alkhoulli, L., Khader, H., Muhareb, H., \& Abu-Shanab, S. et al. (2020). Spiritual Beliefs of Jordanian Adult Patients Receiving Palliative Care. Journal of Religion and Health, 1-13.

Fawaris, H. F. (2021). The role of Muslim women in managing the family during crisis: Corona pandemic as a model. International Journal of Human Rights in Healthcare.

Heath, C., Sommerfield, A., \& von Ungern-Sternberg, B. S. (2020). Resilience strategies to manage psychological distress among healthcare workers during the COVID-19 pandemic: A narrative review. Anaesthesia, 75(10), 1364-1371. doi:10.1111/anae.15180 PMID:32534465

Hu, X., \& Huang, W. (2020). Protecting the psychological well-being of healthcare workers affected by the COVID-19 outbreak: Perspectives from China. Nursing \& Health Sciences, 22(3), 837-838. doi:10.1111/ nhs.12727 PMID:32335991

Jackson, S. E., \& Maslach, C. (1982). After-effects of job-related stress: Families as victims. Journal of Organizational Behavior, 3(1), 63-77. https://doi.org/10.1002/job.4030030106

Klein, L. C., Faraday, M. M., Quigley, K. S., \& Grunberg, N. E. (2004). Gender Differences in Biobehavioral Aftereffects of Stress on Eating, Frustration, and Cardiovascular Responses. Journal of Applied Social Psychology, $34(3), 538-562$.

Lai, J., Ma, S., Wang, Y., Cai, Z., Hu, J., Wei, N., Wu, J., Du, H., Chen, T., Li, R., Tan, H., Kang, L., Yao, L., Huang, M., Wang, H., Wang, G., Liu, Z., \& Hu, S. (2020). Factors Associated With Mental Health Outcomes Among Health Care Workers Exposed to Coronavirus Disease 2019. JAMA Network Open, 3(3), e203976. https://doi.org/10.1001/jamanetworkopen.2020.3976

Liu, C. Y., Yang, Y. Z., Zhang, X. M., Xu, X., Dou, Q. L., \& Zhang, W. W. (2020). The prevalence and influencing factors for anxiety in medical workers fighting COVID-19 in China: A cross-sectional survey. 10.1101/2020.03.05.20032003

Ministry of Health. (2021). COVID-19 Updates in Jordan. https://corona.moh.gov.jo/ar

Möschl, M., Walser, M., Plessow, F., Goschke, T., \& Fischer, R. (2017). Acute stress shifts the balance between controlled and automatic processes in prospective memory. Neurobiology of Learning and Memory, 144(September), 53-67. https://doi.org/10.1016/j.nlm.2017.06.002

Sahashi, Y., Endo, H., Sugimoto, T., Nabeta, T., Nishizaki, K., Kikuchi, A., Matsumoto, S., Sato, H., Goto, T., Hasegawa, K., \& Matsue, Y. (2020). Worries and concerns among healthcare workers during the coronavirus 2019 pandemic: A web-based cross-sectional survey. 10.1101/2020.06.09.20126045

WHO. (2021a). Timeline: WHO's COVID-19 response. World Health Organization. https://www.who.int/ emergencies/diseases/novel-coronavirus-2019/interactive-timeline/\#!

WHO. (2021b). WHO Coronavirus Disease (COVID-19) Dashboard. https://covid19.who.int/

Wu, C., Hu, X., Song, J., Yang, D., Xu, J., Cheng, K., Chen, D., Zhong, M., Jiang, J., Xiong, W., Lang, K., Tao, Y., Lin, X., Shi, G., Lu, L., Pan, L., Xu, L., ... Du, C. (2020). Mental health status and related influencing factors of COVID-19 survivors in Wuhan, China. Clinical and Translational Medicine, 10(2), 1-5. 10.1002/ctm2.52 
Zhu, J., Sun, L., Zhang, L., Wang, H., Fan, A., Yang, B., Li, W., \& Xiao, S. (2020). Prevalence and Influencing Factors of Anxiety and Depression Symptoms in the First-Line Medical Staff Fighting Against COVID-19 in Gansu. Frontiers in Psychiatry, 11(April), 1-6. https://doi.org/10.3389/fpsyt.2020.00386 